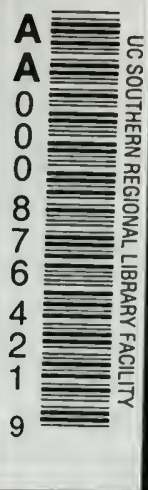


UNIVERSITY OF CALIFORNIA AT LOS ANGELES
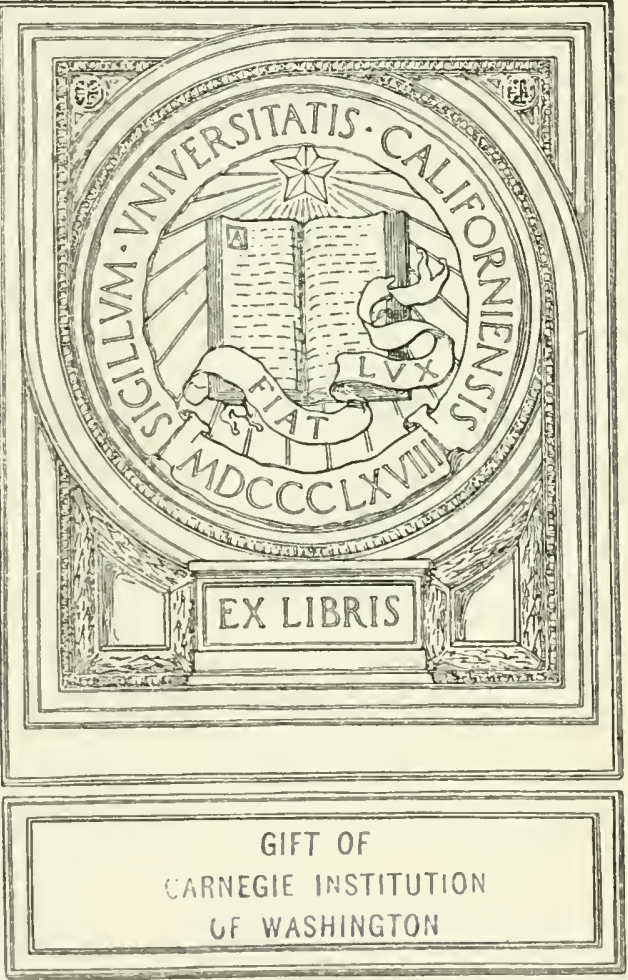






\title{
STAGES IN THE DEVELOPMENT
}

OF

\section{SIUM CICUTAEFOLIUM}

BY

\author{
GEORGE HARRISON SHULL
}

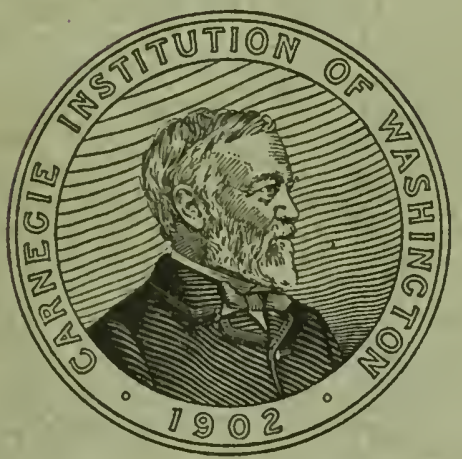

WASHINGTON, D. C. :

Published by the Carnegle Institution of Washington

May, 1905

843 



\section{Stages in the Development}

OF

\section{SiUm Cicutaefolium}

BY

GEORGE HARRISON SHULL

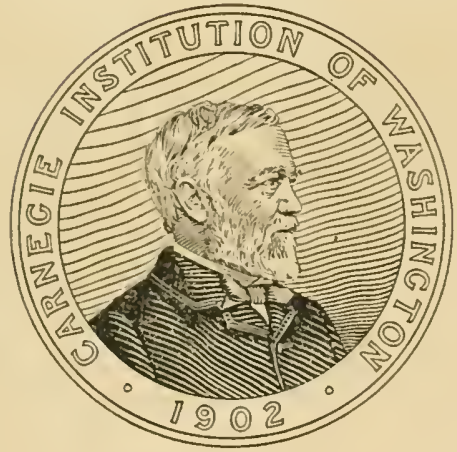

WASHINGTON, D. C. :

Published by the Carnegie Institution of Washington May, 1905 
Carnegie institution of Washington, Publication No. 30.

\section{PAPERS OF STATION FOR EXPERIMENTAL EVOLUTION at COLD SPRING HaRBOR, NEW YORK. NO. 3.}




$$
\begin{aligned}
& Q K \\
& 495 \\
& 448 \\
& 5562= \\
& 1965
\end{aligned}
$$



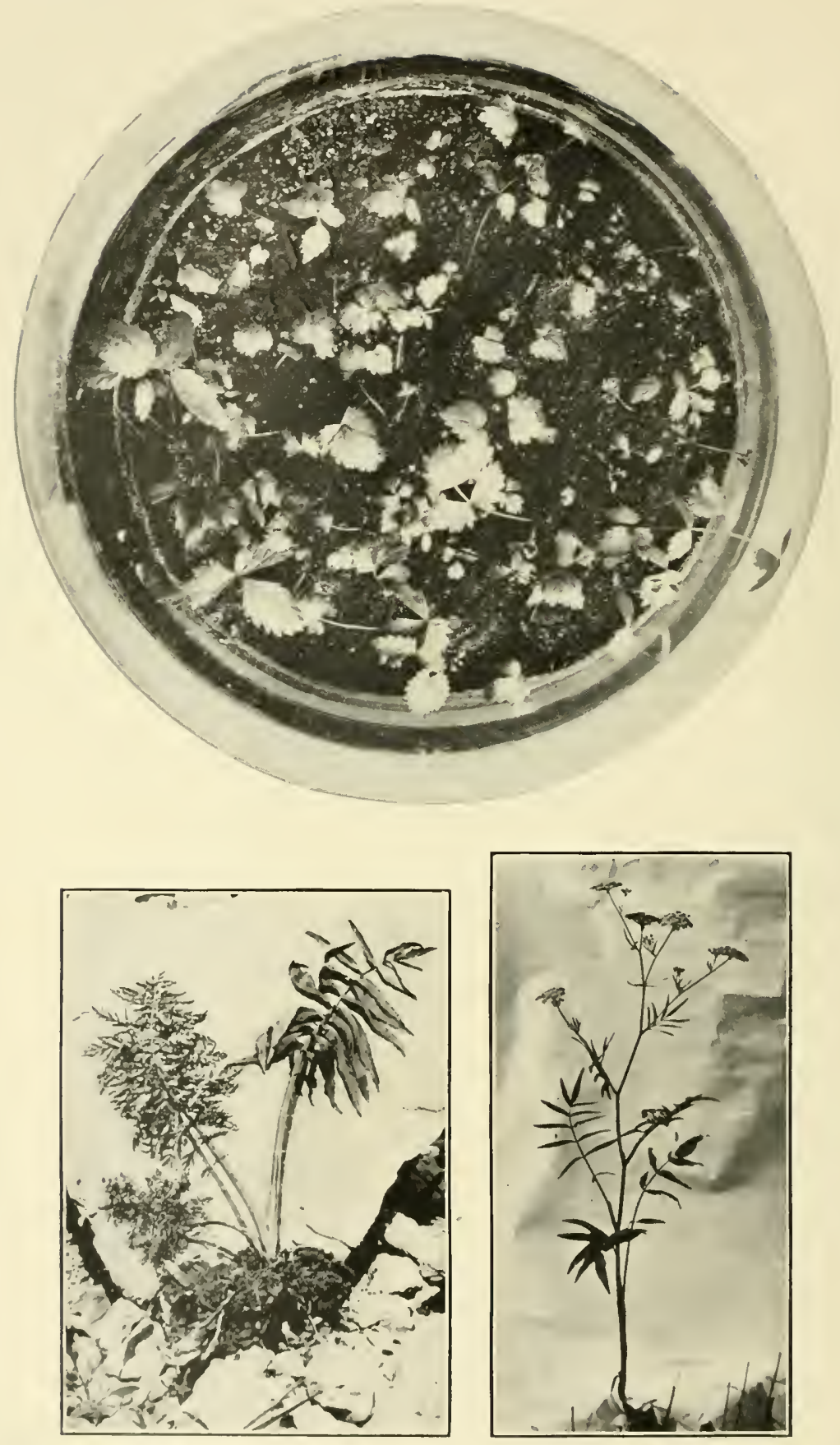

Sium ciculuefolium (imel. A jar of seedlings, photographed at the University of Chicago, October 10, 1903, by Dr. W. J. G. Land; spring-growth of an old plant, photograpined at lockport, 111., Mav 16,1903 , by W. E. Praeger; and a flowering-stem photographed at South Chicago, September 22, 1903. 
growth, modified characters which he believes to be atavistic occur in definite parts of the organism, particularly in the region where resumption of growth takes place. These local modifications he calls "localized stages" and says that the equivalents of these stages "are to be sought in the adults of ancestral groups." In three recent papers in the. American Naturalist, Cushman (1902, 1903, I904) gives the result of studies similar to those of Jackson, and, besides presenting evidence that at the resumption of growth in perennial herbs in the spring these atavistic modifications occur, lays stress upon senescent stages as showing even more primitive conditions than are to be found in the seedling. It may be said, in passing, that this view of the significance of senescent stages does not fully accord with that of Hyatt (I89o, pp. 78, 79; I897, p. 22I), who looked upon senescent stages as indicative of the course any species in question will pursue in the process of degenerative evolution. In Hyatt's view the senescent stages have a prophetic instead of an historic significance, though he recognized, of course, that there are many resemblances between the senescent and the juvenile series.

If the propositions of Hyatt and Cope, of Jackson, and of Cushman are all true, there should be at least three regions in any perennial plant which will agree in presenting ancestral characters-the juvenile leaves following the cotyledons, the earliest formed parts at each renewal of vegetative activity, and the senescent stages approaching and accompanying the inflorescence. In numerous cases there is a general agreement in the forms passed through at these three regions, and no inconsistency arises when they are all looked upon as atavistic, though the mere fact of agreement in the several regions can not be taken as in itself convincing evidence that these characters agree with the adult characters of some ancestral group. On the other hand, certain plants do not show the same modification of leaf-form in the inflorescence that is found in the "nepionic" leaves of the seedling, and it becomes at once evident that no reliance can be placed upon the forms of leaf occurring in any of these regions as having more than the most general significance as indications of ancestral characters.

A plant which most strikingly illustrates this fact is the hemlock water-parsnip (Simm cicutacfolium Gmel.), which presents a great range of leaf-form and passes rather rapidly, sometimes suddenly, from one form to another without repetition, so that each of the regions supposed to tell of ancestral conditions tells a different story. This fact is illustrated in a general way by Plate $I$.

The seedling of Sium cicutacfolium is so different from the adult plant that, except when the two are associated together, its identity 
would scarcely be suspected. I am not aware that this seedling has ever been described, and the striking variations in the form of the juvenile leaves make description difficult.

The cotyledons are quite similar to those of many other of the Umbelliferae, being narrowly oblong or elliptic oblong, rather acutely rounded at the apex, and tapering gradually into a petiole at the base. The petiole and blade together are 1.5 to $2 \mathrm{~cm}$. long and the blade is 2.5 to $4 \mathrm{~mm}$. wide.

The early "nepionic" leaves are extremely variable, but it is rare that they do not consist of a single blade constructed on a somewhat palmate plan. The blade is usually of rounded form and quite variously notched, cut, or lobed. In order to facilitate a systematic investigation of the variation in these leaves they were divided into several more or less artificial groups. The first nepionic leaf in more than I20 unselected individuals* presented forms which were placed in six of these categories, as follows:

(a) About 10.5 per cent were divided palmately into five nearly equal lobes, one or two of which were sometimes slightly notched.

(b) Twenty per cent were 3 -lobed, with the middle lobe 2-notched and the lateral lobes each bifid.

(c) The leaves in the third group were likewise 3-lobed, but the lobes were quite variously notched. Over 28 per cent of the seedlings had the first leaf of this description.

It will be noted that the form of leaf described under $(b)$ is simply a special case of $(c)$, and was separated from it because this was the only form of trilobed leaf which could be so definitely characterized, and because this simple definite type of trilobation is almost wholly limited to the first nepionic leaf.

(d) Over I5 per cent showed the tendency to trilobation by a single cleft on one side, unmatched by a cleft on the opposite side. These will be spoken of as "half 3 -lobed leaves." They pass gradually into a form having one lateral leaflet, and these two conditions were kept together in a single category.

(e) Nearly 25 per cent had a generally rounded, ovate or cordate form, merely dentate, or irregularly cleft in a manner which did not suggest trilobation.

*The seedlings were taken up on two small clumps of earth from their native habitat near Robey, sonth of Chicago, Illinois. The individual seedlings were carefully separated and all were transplanted about $3 \mathrm{~cm}$. apart in a regular pattern in glass dishes. The point of departure for each dish was marked and a number assigned to each seedling, so that drawings made from time to time could be labeled in a manner to allow the progress of each individual to be followed. 
(f) Less than 2 per cent had one pair of lateral leaflets, and may perhaps be looked upon as an extreme form of the 3 -lobed condition of category $(c)$, but $(c)$ is essentially palmate, while $(f)$ is essentially pinnate.

A glance at Plate II will show, better than description, the variability of the first nepionic leaf, and it will also show how truly gratuitous is the division into the categories just described. The leaves were chosen at random from the material at hand, but when more leaves were chosen than could find place in the plate the less dubious forms were discarded in order to show the real difficulties of such a classification and to give a clue to the personal equation of the writer in distinguishing the several categories. The letters A, B, C, etc., illustrate the categories described above under $(a),(b),(c)$, etc.

The first two classes, $(a)$ and $(b)$, are characteristic of the first nepionic leaf. With the exception of these two forms, all the categories described above are represented in each succeeding leaf up to the sixth, and perhaps occasionally in the seventh, and in these later leaves the various types are much more definitely distinguishable, so that there is rarely any question as to where any leaf should be classed. With rare exceptions every leaf after the sixth is pinnate and shows a marked contrast to the great variability of the first leaf, so that in the eighth leaf a very large majority have three pairs of lateral leaflets which closely resemble the typical stem-leaves of the species, except in texture and in the more ovate form of the terminal leaflet.

In the second nepionic leaf (Plate III, 2) trilobation was found in only a little over 5 per cent of the seedlings, or about one-third as frequently as in the first nepionic leaf, but the half 3 -lobed form had increased from 15 per cent to I 8 per cent, the unlobed or irregularly lobed form had increased from 25 per cent to over 6 I per cent, and the form with one pair of lateral leaflets from I.6 per cent to about 5 per cent. Just as the 3 -lobed form was the modal condition of the first nepionic leaf, the unlobed form was the modal condition of the second.

The third nepionic leaf (Plate III, 3) showed a partial return to the 3-lobed condition, and nearly 24 per cent of the specimens were so characterized. The half 3 -lobed form occurred in over 22 per cent, the unlobed or irregularly lobed form in 39 per cent, and the number having a pair of lateral leaflets had increased from 5 per cent in the second leaf to over I 5 per cent in the third. Here, although there was an increase in each of three categories at the expense of the unlobed form, the latter was still the modal form of leaf.

The fourth leaf (Plate III, 4) was 3-lobed in 24 per cent, half 3 -lobed in 15 per cent, unlobed or irregular in nearly 23 per cent, and pinnate 
PLATE II.

A

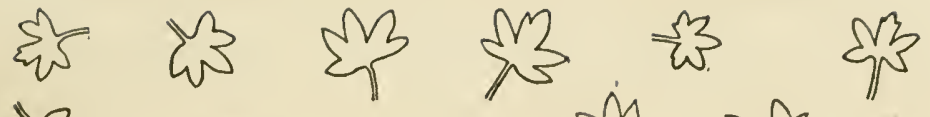

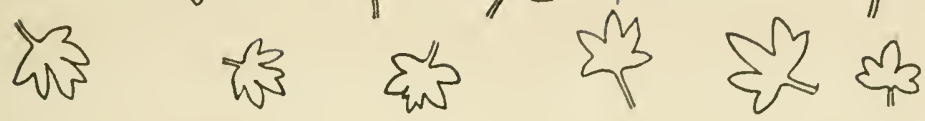

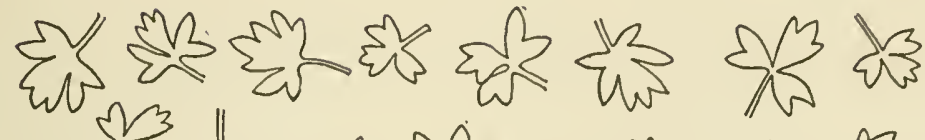

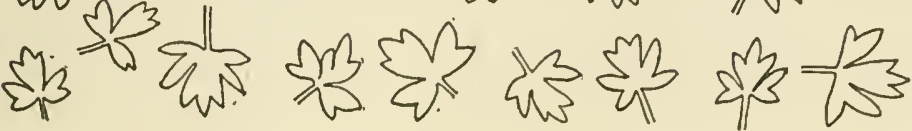

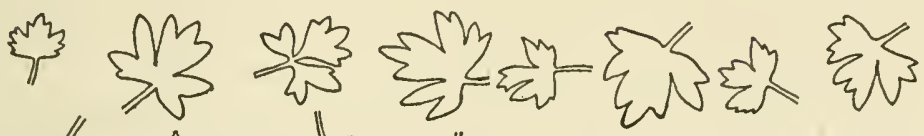

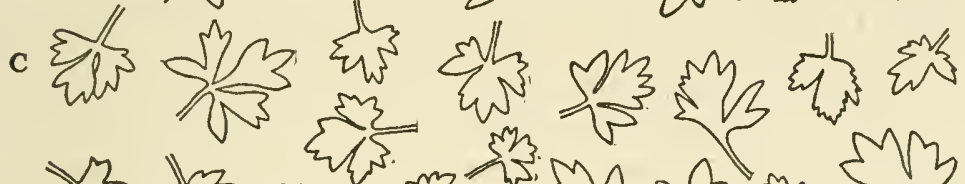

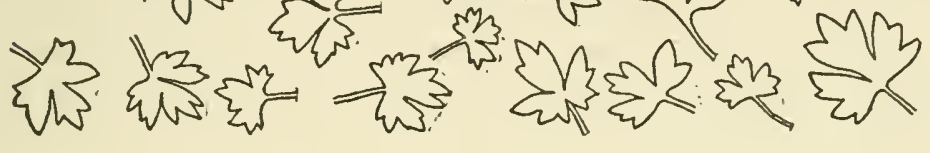

D

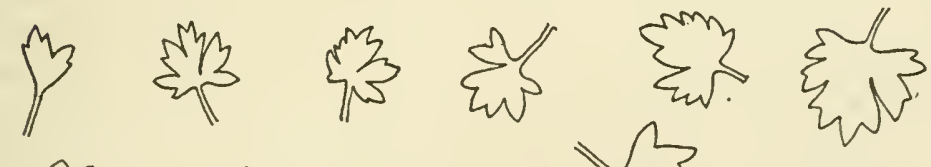

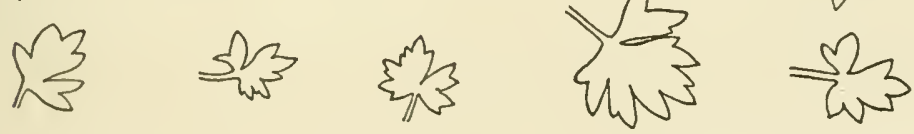

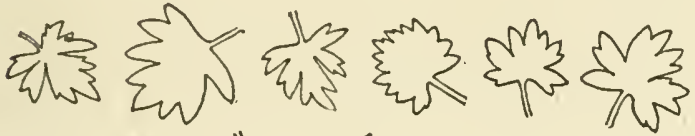

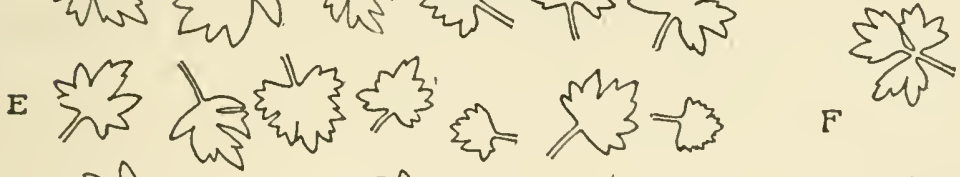

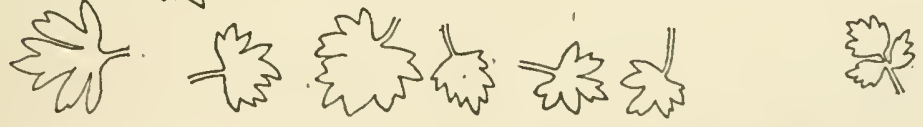

Variation in the first "nepionic" leaf of Sium cicutaefolium. Eight-ninths natural size. All drawn from nature with an Abbe camera. A, B, C, etc., correspond to $(a),(b),(c)$, etc., in the text. 
PLATE III.
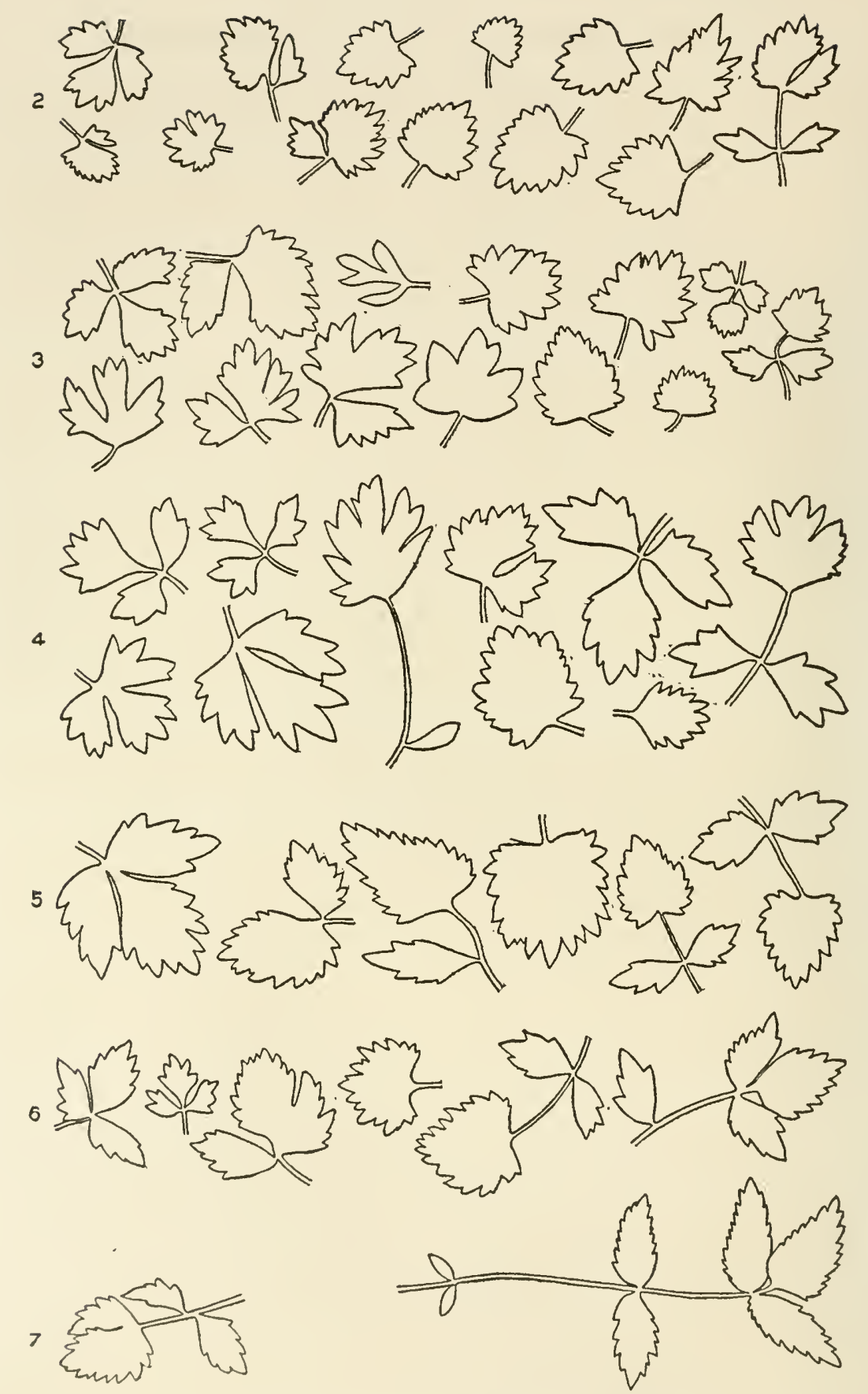

Variation in successive seedling-leaves of Sium cicutaefolium, from the second to the seventh. Eight-ninths natural size. Drawn from nature with an Abbe camera. Numbers represent the position of each group of leaves in the seedling. 
with one pair of lateral leaflets in 30 per cent, this simplest type of pinnation now becoming the modal form of leaf.

In the fifth leaf (Plate III, 5) the percentages of all the types of single blades had considerably decreased and the pinnate had increased, so that now only 4.3 per cent were 3 -lobed and the same number half 3 -lobed, I7 per cent were unlobed or irregular, and more than $7 \mathrm{r}$ per cent had one pair of lateral leaflets, while a little more than 2 per cent had two pairs of leaflets.

The sixth leaf was 3 -lobed in only 3.5 per cent of the specimens examined and the same number were unlobed or irregular. About 7 per cent were half 3 -lobed, nearly 45 per cent had one pair of leaflets, and over $4^{\mathrm{I}}$ per cent had two pairs of leaflets.

In the seventh leaf none were observed which had not at least one pair of leaflets, though it is not improbable that single blades may occur occasionally in the seventh leaf. The specimens in hand showed 27.5 per cent with one pair of leaflets, over 5 I per cent with two pairs of leaflets, and 21.6 per cent with three pairs of leaflets, so that in the seventh nepionic leaf the form with two pairs of lateral leaflets is the modal form.

The eighth leaf presents the same three forms, but only a little over 9 per cent had a single pair of lateral leaflets, i8 per cent had two pairs, and nearly 73 per cent had three pairs.

For more ready comparison these percentages are brought together in the following table. The modal form (empirical) in each leaf is given in full-faced type. The variation of leaf-form occurring in each succeeding nepionic leaf from the second to the seventh is shown in Plate III. The left and right sides of the figure show the extreme range of form found in each leaf. The index figures at the left-hand side of the plate indicate the position of the leaves with reference to the cotyledons.

\begin{tabular}{|c|c|c|c|c|c|c|c|c|c|}
\hline \multirow{2}{*}{\multicolumn{2}{|c|}{ Form of leaf. }} & \multicolumn{8}{|c|}{ Position of leaf. } \\
\hline & & I & 2 & 3 & 4 & 5 & 6 & 7 & 8 \\
\hline (a) & Five-lobed. & 19.5 & & & & & & & \\
\hline (b) & Three-lobed. & 19.4 & & 자 & I. 6 & & & & \\
\hline (c) & Three-lobed. & 28.2 & I5.7 & 23.7 & 22.6 & $4 \cdot 3$ & 3.4 & & ... \\
\hline (d) & Half 3 -lobed. & 15.3 & IS.2 & 22.0 & I 4.5 & 4.3 & 6.9 & & .. \\
\hline$(c)$ & Unlobed or irregular & 25.0 & 61.2 & 39.0 & 22.6 & I 7.0 & 3.4 & & ..... \\
\hline$(f)$ & One pair of leaflets. . & 1.6 & 5.0 & 15.3 & 38.7 & 72.3 & 44.8 & 27.0 & 9.1 \\
\hline$(g)$ & Two pairs of leaflets & & & & & 2.1 & 41.4 & 51.4 & IS.2 \\
\hline (h) & Three pairs of leaflets & & & & & & & 21.6 & 72.7 \\
\hline
\end{tabular}


If the several categories into which these leaves have been divided are examined critically, the following facts will be noted:

I. They are not all of equal value. The second category $(b)$ is only a special case of the third $(c)$. The fourth $(d)$ is transitional between (c) and (e). The fifth (e) is composite, but not readily divisible.

2. Some of the distinctions are qualitative, $i$. e., complexly quantitative, as exemplified by $(b),(c),(e)$, etc. ; others are simply quantitative, as, for example, $(f),(g)$, and $(h)$.

3. They are not arranged in a logical linear series and are incapable of being so arranged. They have been arranged in the order in which they become dominant during development and without reference to their logical relations. The undivided or irregularly cleft blade so characteristic of the second nepionic leaf is the logical termination of a line of development from the 3 -parted leaf through the half 3 -parted, but the pinnate leaf with one pair of lateral leaflets, instead of joining directly to this undivided form which it follows, also comes logically from the 3-parted type. If the progress of the phylogeny of the species is correctly indicated by this ontogenetic series it would appear that after a gradual departure from the ancestral tripartite leaf to the undivided leaf there had been a sudden jump or mutation to the opposite extreme in which the clefts of the tripartite leaf became so exaggerated as to leave the lateral lobes separated from the terminal by a space, thus forming a pinnate leaf. It can not rightly be either affirmed or denied that such mutation took place in the history of the species, but it appears to me that any attempt to interpret the details of ontogenetic development as corresponding so definitely to phylogenetic development would be pressing the analogy to a wholly unwarranted degree.

In fig. I the variation in the several nepionic leaves from the first to the eighth is represented graphically in the form of curves, the several categories being treated as if of equal value. Although, as we have just seen, this is not strictly true, the figure still allows the derivation of at least one interesting conclusion-there is a progressive lessening of the variability from the first leaf onward. The modal class in the first nepionic leaf contained only 28.2 per cent of the individuals, or, if we should include in this class the special form of 3-parted leaf which has been separated as a distinct category, it would still contain only 47.6 per cent of the individuals, while the modal class in the eighth leaf included nearly 73 per cent of the specimens, and the variability within the class was very mucln less in the latter than in the former.

There are several, ways in which we may account for the great variability in the earliest leaf and the decreasing variation with subsequent 
development. If these juvenile leaves do correspond with adult conditions of the past we might suppose that at the time when the species was characterized by a tripartite leaf it was much more variable than it became later, and that the process of evolution acted to give it gradually a more and more fixed character. Or, on the other hand, it might be supposed that the species has been at all times about equally variable, but that by the "law of acceleration" the first nepionic leaf represents a much longer period in the history of the species than does any subsequent leaf. Again, it may be that these leaf-forms are not atavistic, and

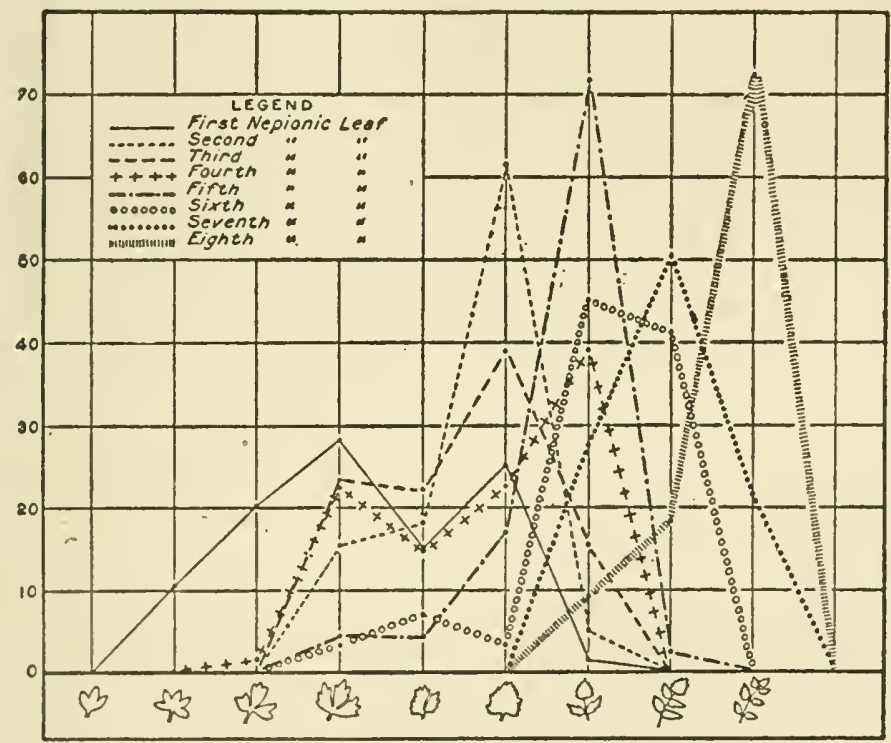

FIG. 1.-Graphic representation of the varlation in the several "neplonlc" leaves of Sium cicutaefolium, from the first to the elghth, inclusive. Ordinates given in per cents.

the wider range of variation may merely represent a greater sensitiveness to minute variations of the internal and external environment. As the plant becomes more and more firmly established it becomes morphologically more sêlf-determinative. In other words, the greater variability and the gradual decrease in variability may be purely physiological facts unrelated in any direct way to the phylogenetic history of the species. It is possible indeed that each of these propositions may represent a partial truth, as they are not mutually exclusive. The species may have been more variable in its adult leaf-form, the law of acceleration may give rise to a greater range of atavistic variation in the earlier 
leaves, and physiological causes may determine which atavistic form shall appear and may in addition give rise to forms or details of form which are in no sense atavistic.

A point in favor of the interpretation of the tripartite leaf as being at least in a general way atavistic may be found in the fact that ternate division of leaves is notably prevalent among the Umbelliferae; but it should not be forgotten that a ternate condition is a necessary logical transitional stage between any "simple" leaf and a pinnate leaf, and its significance must rest solely upon this logical relation. To show how gratuitous is any attempt to draw from the juvenile leaves conclusions regarding the leaf-form in ancestral groups it is only necessary to investigate the conditions found in the few instances in which the ancestry of a species is definitely known. Through the kindness of Dr. D. T. MacDougal, of the New York Botanical Garden, I am enabled to present photographs of the seedlings and adult rosettes of Onagra lamarchiana and $O$. rubrinervis, the former species being the parent of the latter. They represent the closest relationship possible between two species, and yet those who are experienced in their culture separate them with unfailing accuracy in the earliest juvenile stages. A comparison of the seedlings and the adults in Plates IV to VI makes evident the fact that the seedling of Onagra rubrinervis resembles much more closely the adult condition of the same species than either the seedling or the adult condition of its parent species, Onagra lamarckiana.

Turning now to other regions which have been supposed to present ancestral types, particularly to the two regions most strongly exploited by Cushman (1902, 1903, 1904) in his recent papers in the American Naturalist, we find conditions which are totally different from those we have just considered in the juvenile stages. The first of these regions is that at which a perennial herb resumes growth in the spring after hibernation. At the close of the first season from seed the leaflets of Sium cicutaefolium become more or less dissected into narrow segments, as shown in fig. 2. 'This modification is very often apparently related to the more aquatic condition of the habitat, and is in line with modifications in many other species whose dissected leaves appear to be correlated in some way with aquatic conditions; but it can be shown that this change in the form of the leaf of Sium takes place, though less perfectly, when the plants are not supplied with an unusual quantity of water. Plants taken up as seedlings in Junc and grown under mesophytic conditions in the window of a laboratory at the University of Chicago and later in the conservatory of the same showed dissection of the leaves similar to that exhibited by plants that were submerged in imitation of the effects of autumn rains. 
PLATE IV

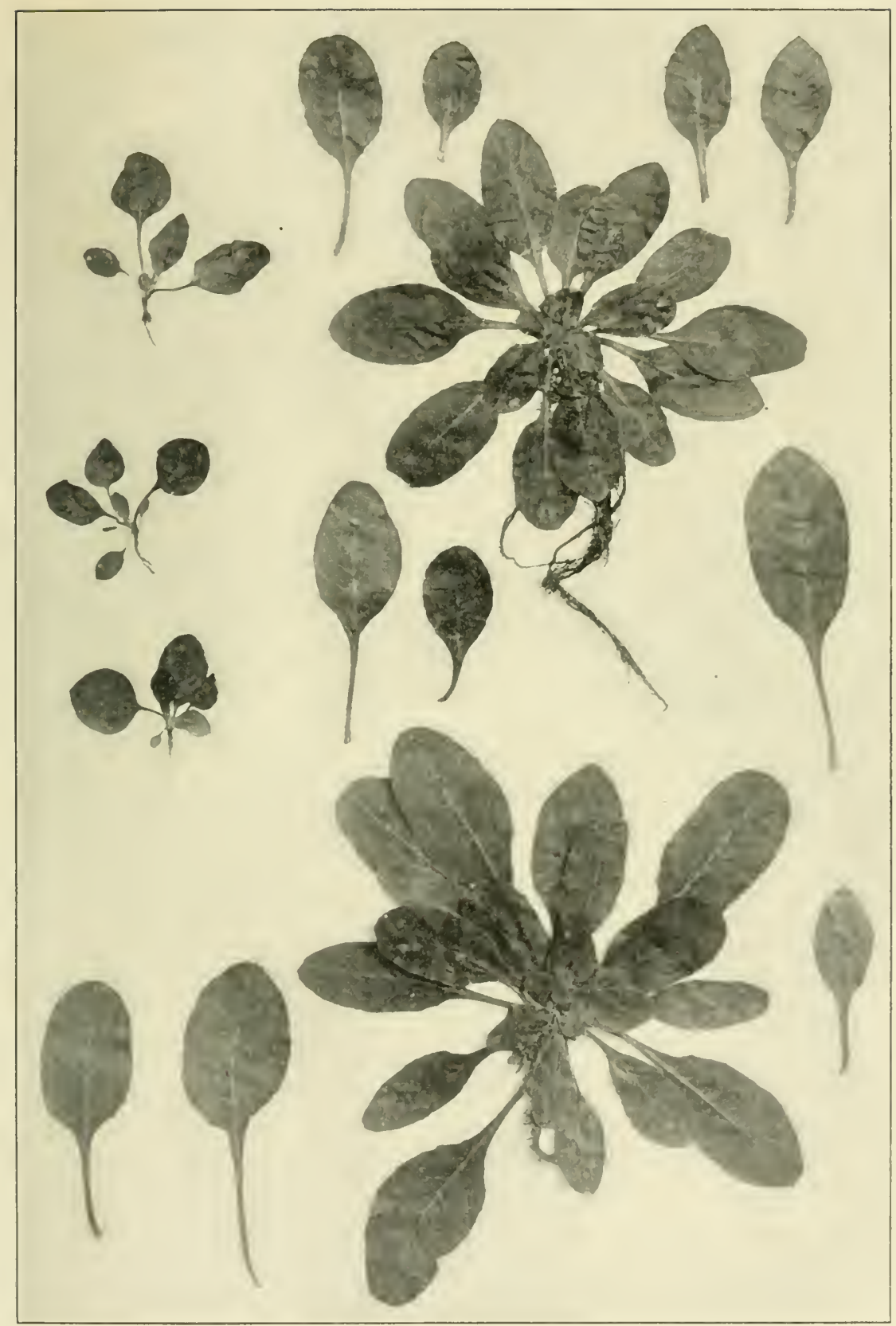

Seedlings of Onagra lamarckiana, grown at the New York Botanical Garden. Photograph supplied br. Dr. D. T. MacDougal. 

PLATE V.

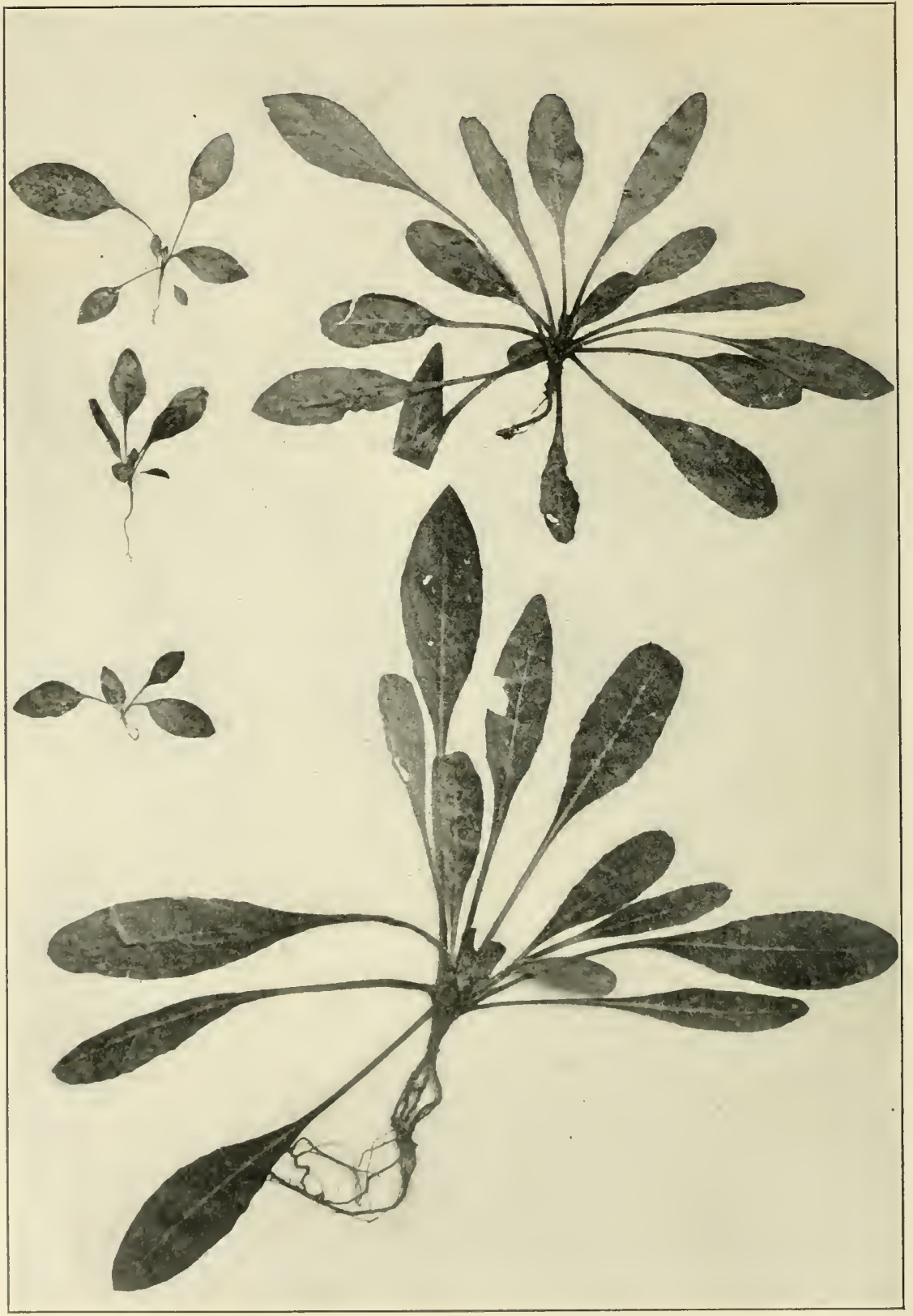

Seedlings of Onagra mbrinervis grown at the New York Botanical Garden. Photograph supplied by Dr. D. T. MacDougal. 
PLATE VI.
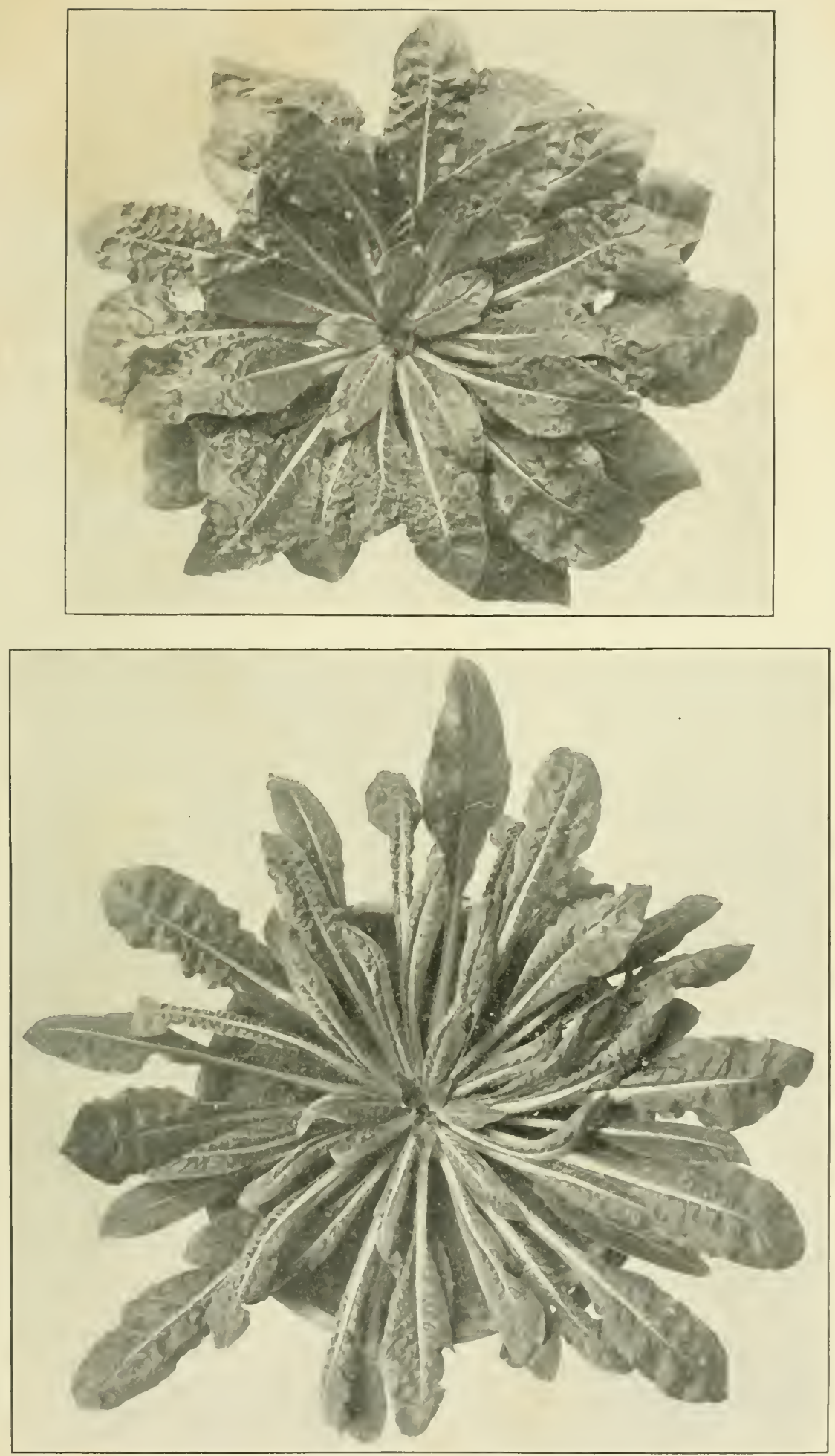

Large rosettes of Onagra lamarckiana (upper) and O. rubrinerzis (lower), grown at the New York Botanical Garden. Photographs supplied by Dr. D. T. MacDougal. 

Burns (1904) has recently demonstrated a similar independence from aquatic conditions, in the dissected leaf of Proserpinaca palustris, though McCallum (1902) had looked upon it as a direct response to the dilution of the protoplasm brought about by the abundance of water and the stoppage of transpiration. Burns considers the dissected leaf of Proscrpinaca as a juvenile type, but this is certainly not the case in Sium cicutacfolium.

A more pronounced, even extreme, dissection of the leaves characterizes the resumption of growth in the spring (Plates I and VII), so that

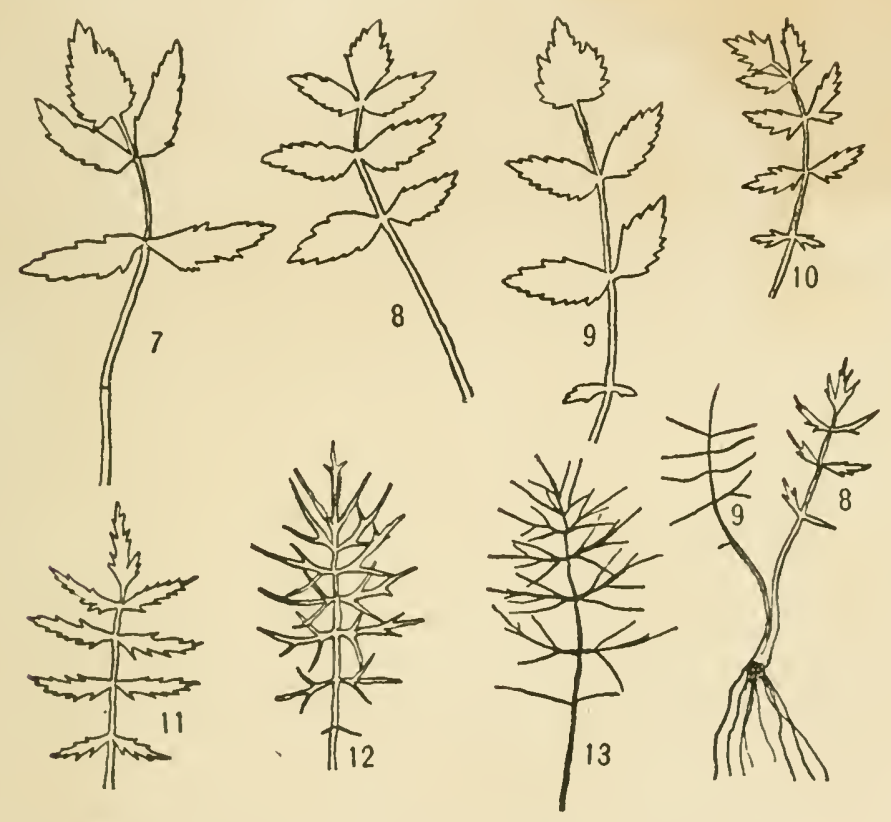

Fig. 2.-Autumnal modification of leares in the seedlings of Sium cicutaefolium. Numbers represent the position of each leaf in the serles, beginning with the first neplonic lear. Three-fourths natural size.

in so far as this region indicates the ancestry of the species the ancient Siums should have resembled a fennel (Focniculum) or a parsley (Lomatium). These dissected leaves are rarely seen by the systematist who works only with pressed material, as one may convince himself by looking through the specimens of Sium in any large hrebarium. Of more than 100 specimens of this genus in the herbarium of the New York Botanical Garden not one showed these dissected leaves. The change from dissected leaves to the simply pinnate leaves with linear, lanceolate 
or lance-ovate, sharply serrated leaflets characteristic of the typical leaf of the stem, is very sudden (see Plates I and VII), and would again indicate a remarkable mutation if the course or ontogenetic development agrees with the phylogenetic.

In fairness to Cushman it should be said that while this discussion of the early spring growth is based on a literal interpretation of his papers, it evidently misrepresents his intention. The condition in Sium is analogous to that in the rosette plants, in which the writer had to look carefully beneath the rosette to find the "primitive" leaves. If he had examined the rosettes at some time during the preceding summer or autumn, when they were just beginning to develop, he would have found less difficulty in securing the leaves for which he was looking. The dissected leaves in old specimens of Sium result from the rejuvenation of axillary buds at the base of the flowering stem, and it will be seen later that the first leaves of these buds were of a more juvenile type, but that they belong to the autumn growth instead of the period of renewed vegetative activity in the spring.

When we examine the senescent stages approaching the inflorescence a series of forms is found entirely different from either of those already considered, and yet according to Cushman it is in the region of the inflorescence that we should be able to trace phylogeny to its earliest stages. During senescence the leaves of Sium cicutaefolium present a marked contrast in every particular to the juvenile stages. The progressive changes (fig. 3) present a simple linear series instead of the complex series seen in the seedlings, and there is an increasing constancy of form as senescence progresses instead of the increasing variability which should be expected if the senescent stages repeat the same story as that told by the juvenile stages, but in inverse order. Thus in 34 adult plants examined with reference to this point the second leaf below the principal inflorescence ( $n-4$, figs. 3 and 6 ) had three pairs of leaflets in Io per cent, two pairs in 56 per cent, and one pair in 34 per cent; the leaf subtending the primary umbel $(n-3)$ had one pair of leaflets in more than 70 per cent; and the peduncle arising axillary to this highest leaf of the principal axis bore a bract $(n-2)$ having a single lance-linear blade in over 80 per cent. In vigorous plants peduncles of tertiary or still higher orders occur, and the bracts ( $n-I$ and $n$ ) on these show a regular reduction from the form just described as predominant on the secondary peduncles to small awl-shaped structures which apparently correspond to the base of the petiole and leaf-sheath of the earlier stem-leaves, the blade having completely disappeared. 
Besides these differences in form between the senescent and the juvenile leaves, there is quite as marked difference in the texture, venation, etc. The dissected leaf has already been spoken of as having a form not rarely associated with aquatic habitats. Similarly the juvenile and senescent leaves have forms and textures usually associated with mesophytic and xerophytic habitats, respectively, the reduction of the blade, firm texture, and strong cuticularization of the stem-leaves being in marked contrast with the broad blades and delicate texture of the juvenile leaves. It will not be surprising to find that each of these three

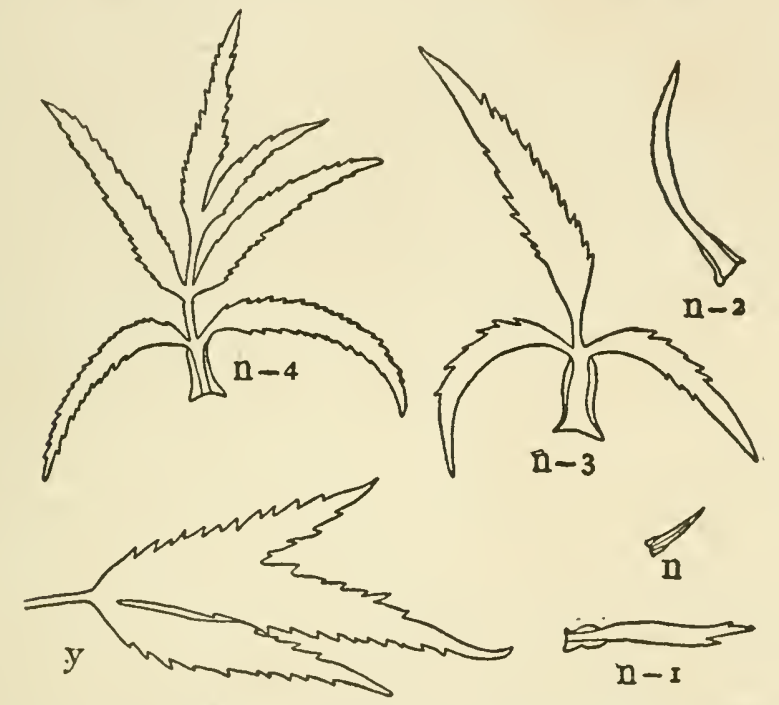

FIG. 3.-The senescent serles of leaf-forms in Sium cicutaefolium. Numbered downward from $n$, the most reduced leaf found in the Inflorescence; $y$ a terminal leaflet showing incomplete differentiation of a pair of lateral leaflets. Two-thirds natural slze.

types of leaves is associated with just the conditions of environment to which it would appear to be adapted. The seedling develops in the shade of other plants during the summer, when the substratum is less wet; the dissected leaves occur in autumn and spring, when the favorite habitats of the plant are apt to be supersaturated or flooded with water; and the stem-leaves are raised above the substratum, where they are more exposed to the drying influences of wind, light, etc., and at the same time farther from their water-supply.

But too much stress can easily be placed upon external appearance as evidence of adaptation, and the dissected leaves, which suggest by their form an adaptation to hydrophytic conditions, do not bear out the suggestion when put to the test. They are unable to do sufficient pho- 
tosynthetic work when submerged to allow the plant to continue its growth, and death speedily follows complete submergence. It might be assumed that the dissection is a product of the environment instead of an adaptation to it, and the apparent correlation of these three stages of Sium with different environmental conditions would accord well with the contention of Klebs (1903) and others that external factors are directly determinative of the form and activities of plants. But the plants which appear to demonstrate this proposition are quite exceptional. In Sium cicutaefolium this direct relation between the form and the environment proves to be only apparent, and this species seems to agree with the vast majority of plants in presenting a rather definite cycle of development which it passes through whenever the environment supplies conditions which are favorable to growth. In such cases the environment is only indirectly determinative of vegetative activities. It supplies the energy, but the mechanism of the protoplasm determines what shall be the product, just as the muscles of the hand and arm used

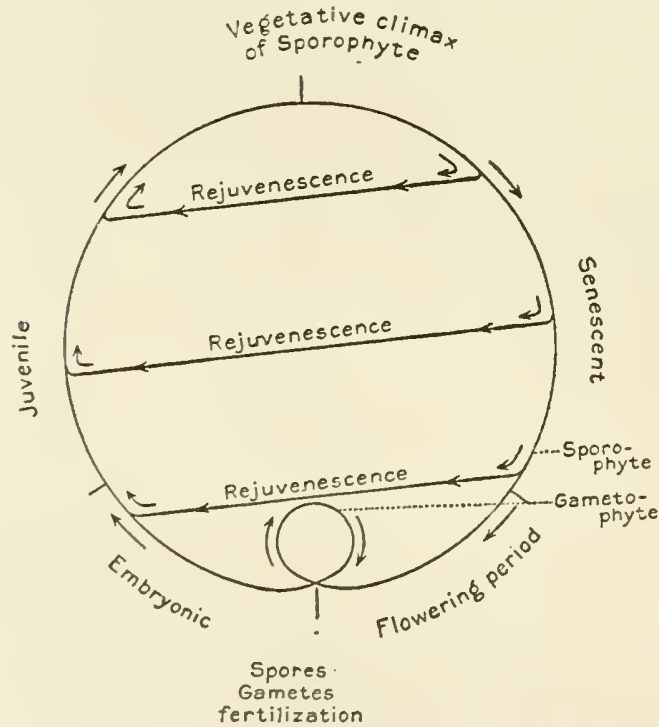

Firt.4,-Dlagram of the llfe-cycle of a spermatophyte, showing the relation of the process of rejuvenesrence ats a "short-cut" across the cycle. Upper "rejurenescence" Inne may represent the rejuvenescence of buds at bake of stem (fig. 7); the lower, the prollferatlons of the flower-buds (figs. 8 and 9 ). in winding a clock supply the power which is converted by the peculiar mechanism of the clock into movement of the hands, ticking of the escapement, and striking of the hour.

When a cycle of vegetative activity comes to a close with the senescent stages it can be repeated only as a result of some process of rejuvenescence. Fertilization and seed production are to be looked upon as preparatory to or part of the most common process of rejuvenescence, as was pointed out long ago by Alexander Braun (185I), but this is not the only manner in which it may be brought about. Whenever a bud grows immediately without a resting period there is no sign of rejuvenescence and it con- 
tinues the cycle on to the close of the senescent series, beginning at or slightly in advance of the stage attained by the axis at the level from which the bud springs. But when it fails to develop at once it can not

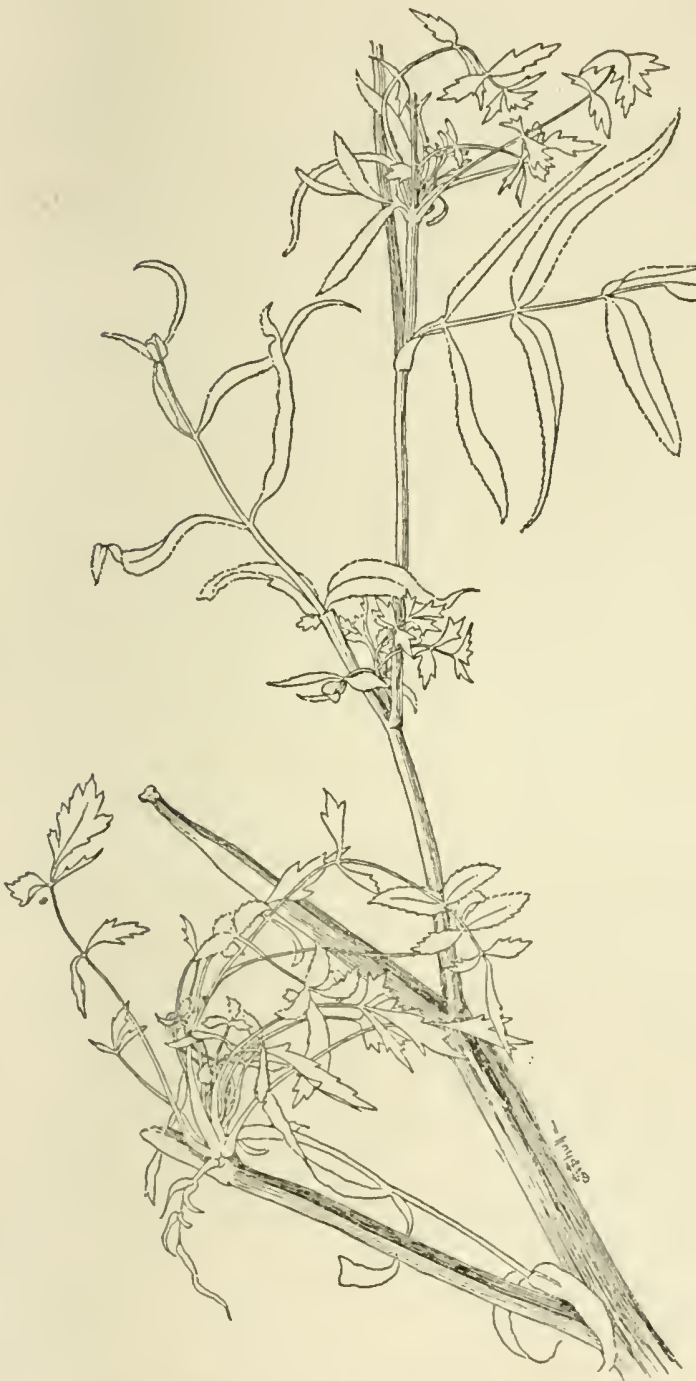

rig. 5.-Part of the stem of a specimen of Sium cicutrefolium with three rejuvenated buds. Drawn by J. Marion Shull from a photograph. resume activity except through a process of rejuvenescence, which throws its development back to some earlier point in the cycle, and always at least as far down the juvenile side of the cycle as the origin of the bud is down the senescent side, a relation which is clearly indicated by the slant of the "rejuvenescence" lines in the diagram (fig. 4).

It is this less differentiated, juvenile condition which usually occurs when a resting bud is reawakened into active development which suggested to Jackson (I899) his conception of localized stages having phylogenetic significance.

Some cases of rejuvenescence were observed in a specimen of Sium cicutacfolium which had been torn up by the roots and thrown down in such a way as to submerge the upper portion of the stem and the immature inflorescence. The axillary buds of the upper part of the stem, which might otherwise have produced secondary branches of the inflorescence, and which would then have 
borne only the closing members of the senescent series of leaf-forms (fig. 3), were rejuvenated as a result of the submergence and made to begin a new series, the early members of which show the most interesting transitions from the senescent to the juvenile forms. Two of these rejuvenations are shown in figs. 5 and 6 . The two leaves $(n-4, n-5)$

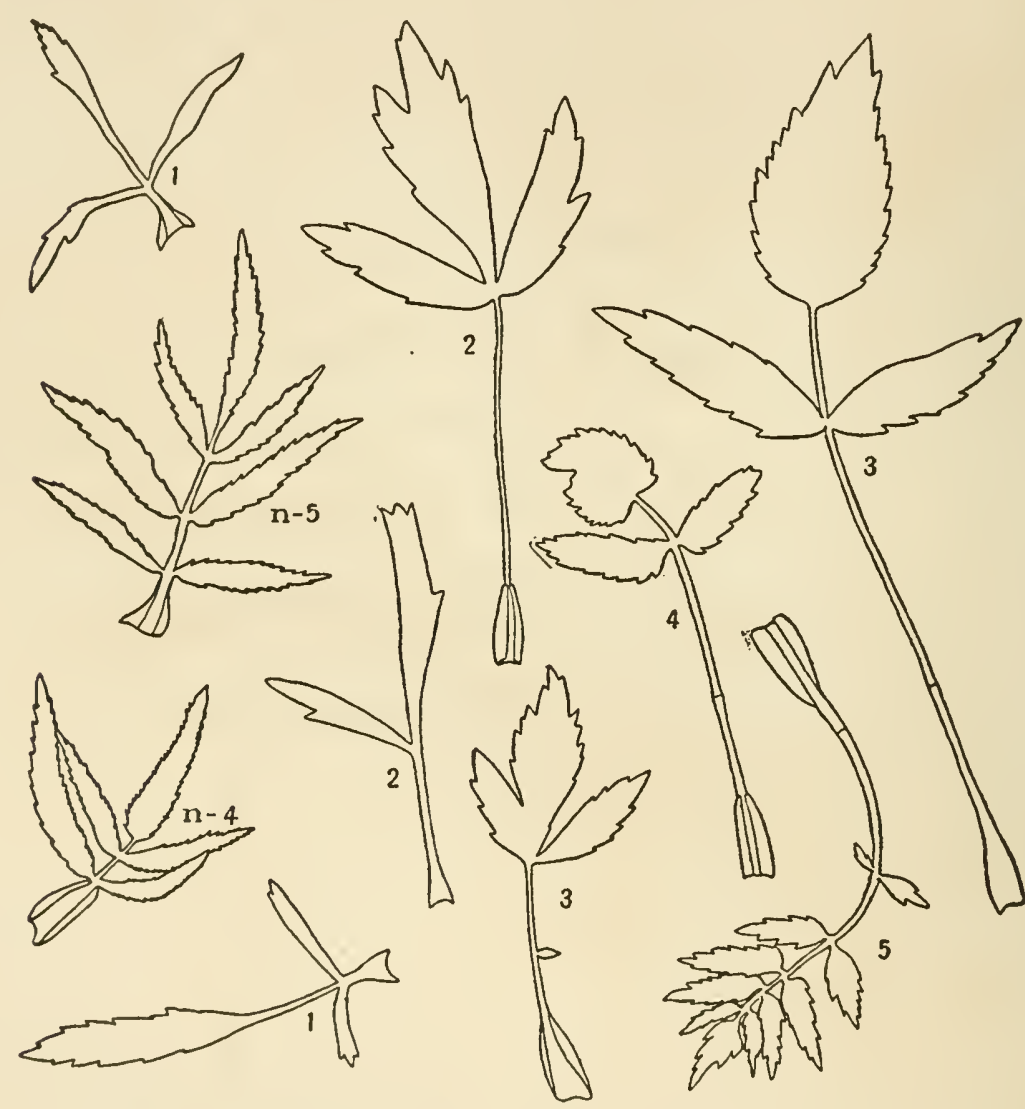

FiG. 6.-Two rejuvenated buds from the upper portion of a stem of Sium cicutaefolium: $n-5$ and $n-4$, leaves to whlch the buds were axillary. Numbers represent the position of each leaf in the bud. Two thirds natural size.

at the left in fig. 6 are the leaves to which the two rejuvenations shown in the same figure were axillary. Unrejuvenated, the first leaf produced by each of these buds would have been a pinnate leaf of exactly the same character as the leaf to which the bud was axillary, but with a less number of leaflets. Instead of this we see in each case a leaf having the same arrangement of parts, to be sure, but greatly modified in 


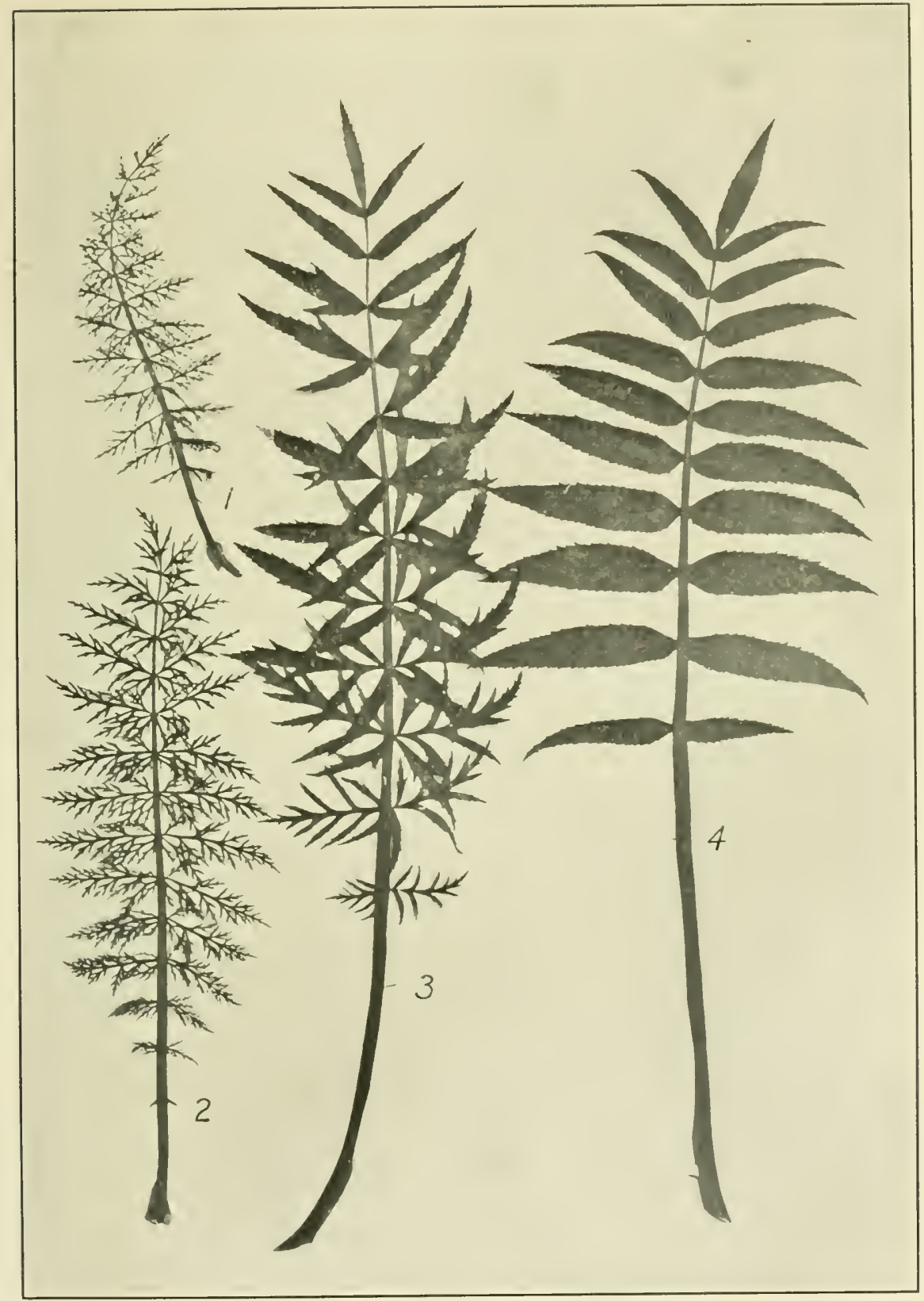

Sium cicutacfolium Gmel. The first four leaves of the spring-growth of an old specimen. Two-fifths natural size. Photographed April, ico5, from a specimen taken into the house February 25, 1905. 

the direction of the tripartite leaf, which will be recalled as the modal condition in the first nepionic leaf. In the second leaf in the one case a form similarly transitional to the half-tripartite leaf occurred, and in the other case the juvenile type of 3 -lobed leaf was perfected. With the third leaf in the one rejuvenation and the fourth in the other, a pinnate form was produced which corresponded in every way with that seen above to be the modal condition of the fifth nepionic leaf. This was as far as one of these rejuvenations was followed. In the other the fifth leaf had five pairs of leaflets, a degree of differentiation not

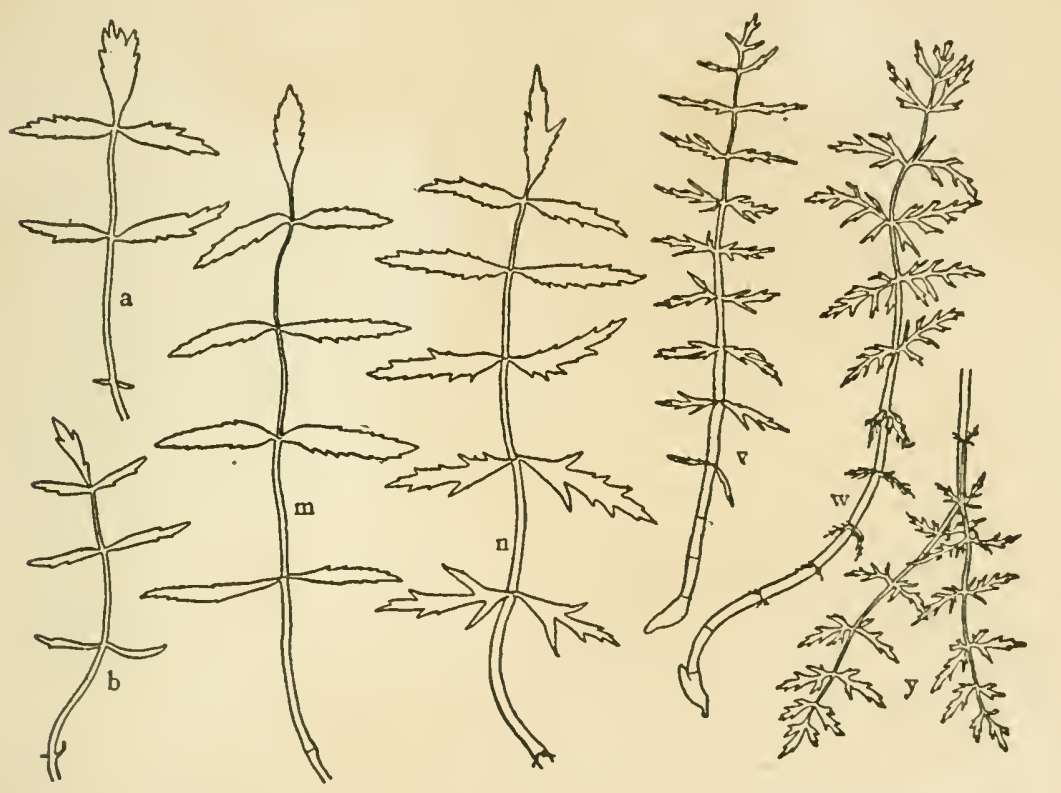

Frg.7,-Leaves of a rejurenated bud from near the base of a stem of Sium cicutaefolium. Letters represent in a general way the position of each leaf in the rejuvenation; $y$, an abnormally divided blade. Four-ninths natural size.

usually attained during the first year from seed. Later these rejuvenations produced the dissected leaves characteristic of the autumn and early spring growth.

Lateral buds at the base of the flowering stems are regularly rejuvenated in the autumn, and the first leaves are pinnate with one or several pairs of undivided leaflets and are followed by a linear series leading more or less quickly to the dissected condition (fig. 7). It will be noted that these basal rejuvenations never present leaves suggestive of the earliest juvenile stages, as is the case in the rejuvenescence of buds 
near the inflorescence, probably because their senescence has not progressed so far.

Senescence reaches its culmination in the region of the flower. Remarkably interesting conditions were found in the inflorescence men-

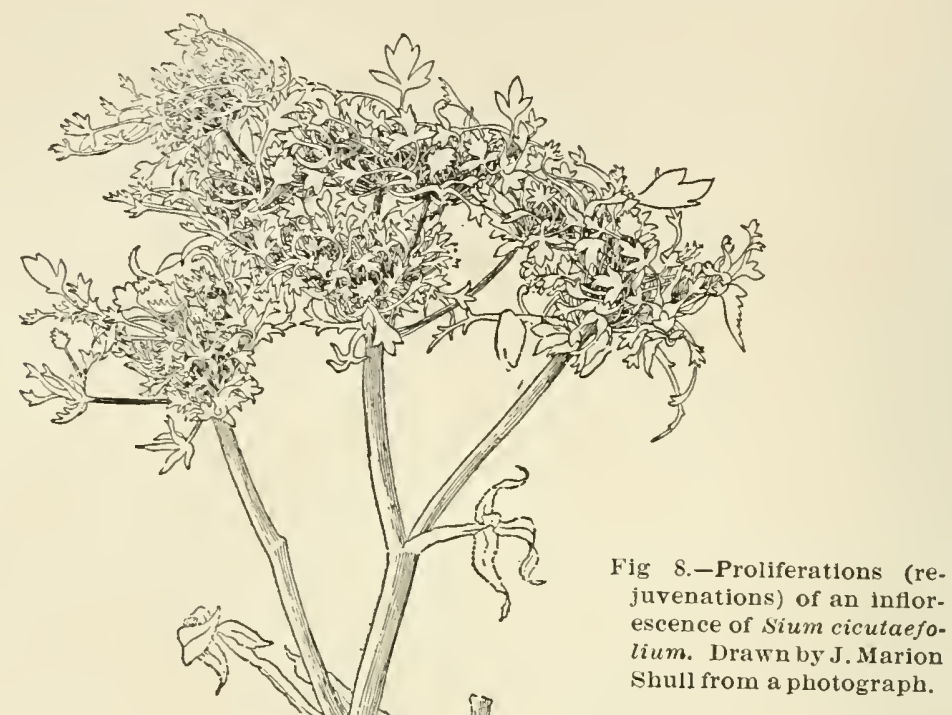

tioned above which had been submerged before the development of the flowers. All the flowers had given place to proliferations (fig. 8), i. e., the flower-buds were rejuvenated by the submergence; and just as the flowers represent the extreme of the senescent condition, the proliferations presented extreme juvenile conditions, showing several types of leaf which are simpler than any which were found in the seedlings, and

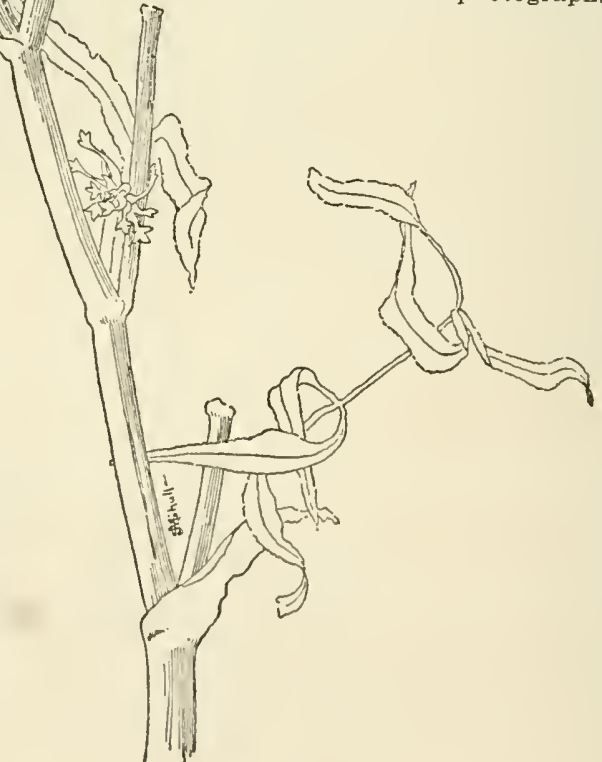
usually reaching the condition of the first nepionic leaf at the third or fourth leaf of the proliferation. Some of the proliferations were more 
precocious than this, however, and all showed a much more rapid development of the dissected form than is seen in the seedling.

The simplest leaf presented by these proliferations (fig. 9) was a minute oblong undivided structure which might be slightly widened and flattened in the distal half, but otherwise showed no distinction of blade and petiole. This might be followed by another undivided leaf

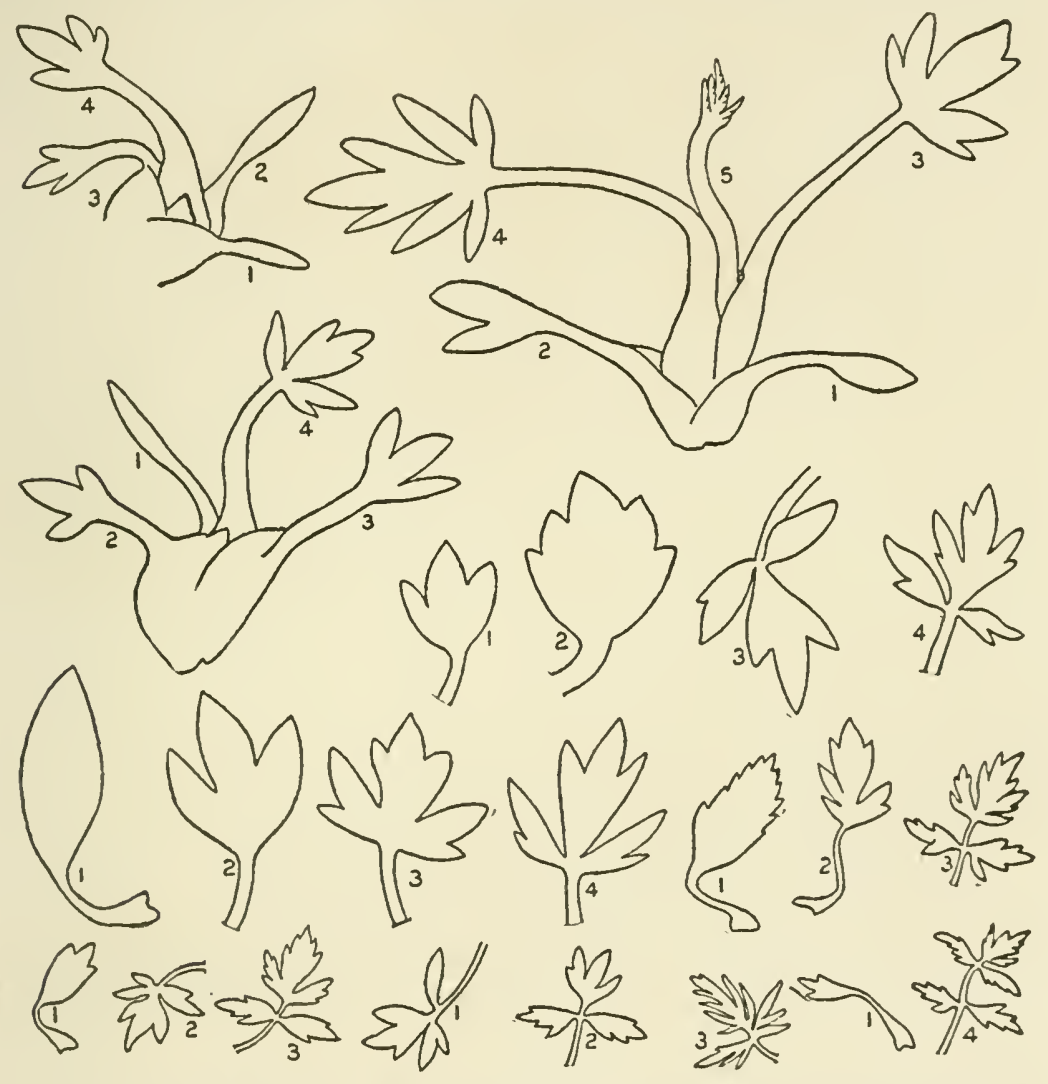

FIG. 9.-Proliferations from an inflorescence of Sium cicutaefolium. Fumbers show position of each leaf in its own prolfferation. Vartously magnifled, $\times 5$ to $\times 8$.

with a wider, elliptic blade. Then there might be a leaf having one or a pair of simple lateral lobes, followed perhaps by the 5-lobed leaf or the form which has been described as the simplest type of 3-lobed leaf occurring in the scedling, having a 2-notched terminal lobe and bifid lateral lobes. Whether the juvenile stages are atavistic or not, these early leaves of the proliferations logically precede and lead up to them, and carry us down the series to the simplest possible type of leaf. 
The rejuvenescence of all these buds as the result of a change from an aerial to an aquatic habitat is in perfect agreement with Burns's (1904) interpretation of the changes induced in a similar way in Proserpinaca palustris and very greatly strengthens his position. The fact that the juvenile leaves of that species are finely dissected in the manner so frequently found in the climactic or ephebolic stages of typical submerged plants is either purely a coincidence or may be related in some unknown way to the past environmental relations of the species, as suggested by Goebel (1899-1901, p. 546). In Simm, where the juvenile leaf is not at all of the hydrophytic type, submergence in water does not produce a dissected, hydrophytic leaf, but the mesophytic form of leaf characteristic of the Sium seedling.

This change of view regarding the effect of water in producing the modified leaf-form of these plants does not detract in the least from the value of the negative results of McCallum's (1902) investigation into the nature of the stimulus involved, but gives those results a bearing on the phenomenon of rejuvenescence instead of the change from a terrestrial to an aquatic type of leaf. To ascribe a phenomenon to good or poor vegetative conditions (Burns, I904, p. 586) does not yet trace it very near to its ultimate cause or causes, but perhaps is as definite as the present state of our knowledge regarding rejuvenescence would warrant. The great vigor of the rejuvenated buds in Sium is scarcely consistent with the view that they are due to starvation or any other poor vegetative conditions, and, indeed, when we find flower-buds, representing as they do the low ebb of vegetative vigor, suddenly a wakened into a new cycle of vegetative development we should assume that they have found good rather than poor vegetative conditions.

It is evident that a distinction must be made here between the cause of rejuvenescence or the reawakening into the ascending side of the vegetative cycle and the cause which determines just what point in the cycle shall be attained in any specific case. I would offer the tentative suggestions, $(a)$ that a process of senescence resulting in a checking or a cessation of growth is a necessary condition antecedent to rejuvenescence, and $(b)$ that the cause of the reawakening may be due to either or both of two complex factors, namely, an increase in available food-cquivalent and an increased lability or mobility (perlaps largely fluidity) of the protoplasmic substances. The former may be predominantly operative when lateral buds are forced into development by checking the growth of a terminal bud, and the latter may be the dominant factor in cases of submergence. (c) The causes which determine the point in the cycle which shall be attained under any specific condi- 
tion may well be the relative degree of one or other of these factors or of their resultant, as compared with that necessary for the production of the climax type of leaf of the adult plant. This is essentially in accord with Burns's (r904, p. 586) suggestion of poor vegetative conditions, and also with the earlier observations of Cushman ( 1902, p. 885) that weak individuals and those growing on poor soil or with insufficient moisture present earlier stages than do more vigorous specimens or those growing under more favorable conditions with respect to soil and water-supply. As applied to Proserpinaca this would mean that the juvenile type of leaf in the submerged plant is primarily the result of protoplasmic dilution, but that the failure to attain the adult condition is due to less favorable relations as to food-supply. Ordinarily in submerged plants of Proserpinaca these two factors may be conceived to balance each other in such a way as to produce the dissected leaf continuously, but an unusually vigorous plant may be able to provide a food-supply sufficient to overbalance the effect of dilution, and so give rise to the adult type of leaf which is occasionally seen even in submerged plants. When the dissected leaf is produced in aerial parts it is primarily due to a condition as to food supply better than that available in the resting condition, but not equal to that necessary for the production of the adult leaf-type. With the return of spring, conditions for food-manufacture are improved and the adult leaf appears at once.

An explanation of scnescence in the same terms would ascribe it to decreasing lability or fluidity unaccompanied by a compensatory increase in the available food-equivalent-a condition coming just as fully under the head of poor vegetative conditions as does that producing the juvenile stages.

Not only are different regions of the axis supposed to bear leaves characteristic of different periods in the history of the species, but it is maintained by both Jackson (1899) and Cushman (1902, 1903) that certain parts of the leaf, especially the apical region, likewise show atavistic conditions. Leaving wholly aside for the present the relation between the parts of the present adult leaf and the form of the ancestral leaf, the question involved in this proposition is the localization of the differentiative activities in the leaf. The simpler character of the apical region in many leaves is undeniable, and it may correspond in certain cases, therefore, with ancestral conditions, though this has not been proved in any specific case. But the simplicity of the apical region has led both of these writcrs into crror when they conclude that new characters arise at the base of the leaf. After cxamining many leaves and 
also the figures upon which Jackson and Cushman base their conclusions, I am convinced that with possible rare exceptions the new character added to a leaf having a single blade and an entire margin consists in an indentation or an incision rather than an outgrowth, and that, in general, increased complexity is brought about by an increasing number and depth of these incisions, which do not and can not occur at the base, but must occur above it. That part of the base below the lowest incision is characterized by an entire margin and is "primitive," therefore, in the same sense as is that part of the apex above the highest incision. Just as Cushman (I903, p. 244) noted that emarginate apexes may develop from acute ones in Astragalus adsurgens, so in cases like that of his Arabis albida, in which truncate and cordate bases occur in a series beginning with attenuate bases, these forms are late modifications of a tapering base, due to the excess of marginal growth as compared with that of the mid-rib. Although the basal margin is thus distorted from its original direction, it retains its unbroken "primitive" character.

The figures which illustrate Cushman's papers show these facts so clearly that it seems strange that he should not have recognized them. Particularly in Sibbaldiopsis (Potentilla) tridenata, Artemisia stelleriana, and Sanguisorba (Poterium) canadensis is it diffcult to harmonize his figures with his statement that new characters are produced at basc. In the first two of these plants the new character, as I under-

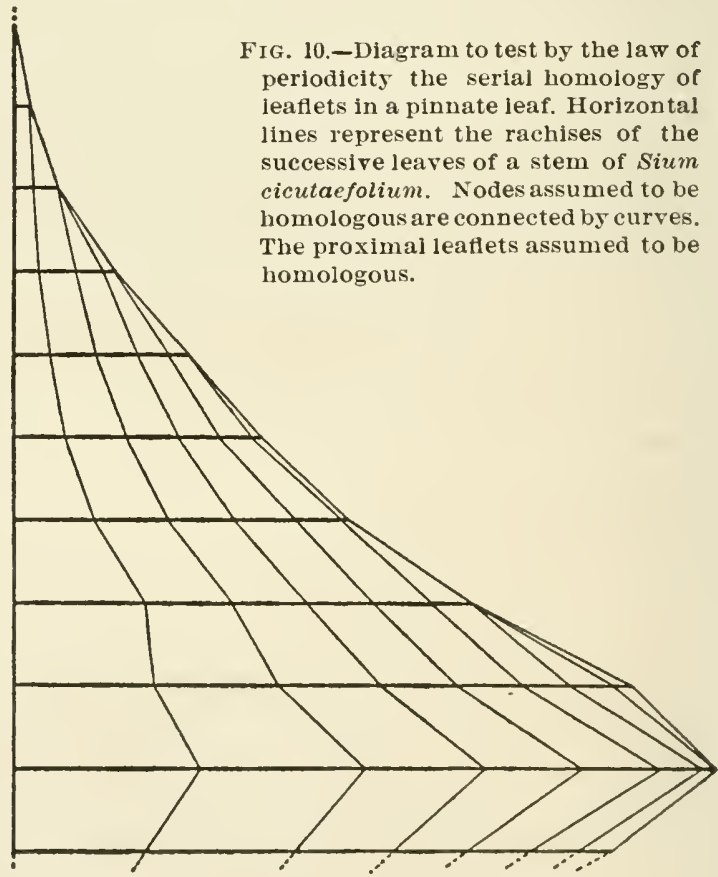
stand it, consists in the appearance of two small indentations very near the apex. In Sanguisorba canadensis the leaf is pinnate, and in the later stages of the senescent serics each proximal leaflet presents in each leaf a peculiar inequilateral form, though the number of leaflets de- 
creases regularly as the inflorescence is approached. In order to make this leaf fit his view of basal differentiation, Cushman (I903, p. 254) assumes that as each proximal leaflet disappears the next higher leaflet takes on this same inequilateral form.

According to this view the proximal leaflets are the newest. If, on the other hand, it be conceived that the leaflets appear in apical succession by the division of the terminal leaflet, and that they disappear through the loss of one pair of incisions after another, proceeding now basipetally, the proximal leaflets, which have in every late senescent leaf the same peculiar shape, will be the oldest instead of the newest, and the inequilateral leaflets of one leaf will be homologous with those of all of the other leaves. In the latter case it would occasion no surprise to find that these leaflets show a well-established form which occurs with considerable constancy in each succeeding leaf. If these proximal leaflets were in a state of perpetual nascence and evanescence we would expect the process to result in frequent imperfect or incom-

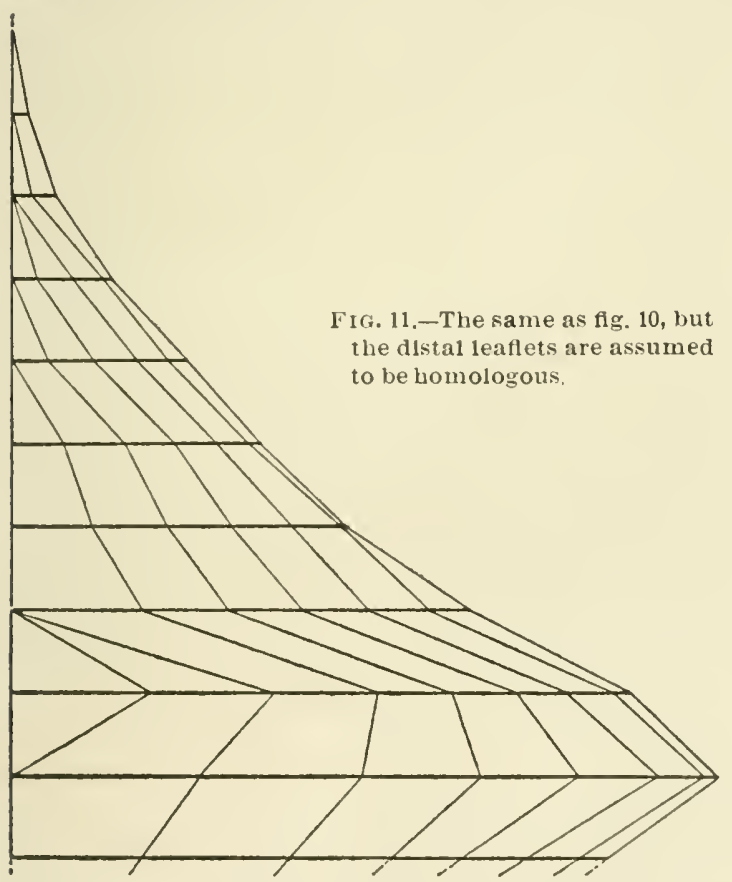
plete differentiations and consequent great variation, a condition never realized.

Every one will recall frequent instances in which the terminal leaflet of a pinnate leaf showed imperfect formation of lateral leaflets by incisions of greater or less depth near its base $(11-4$ and $y$, fig. 3 ), and every degree of division will have been noted, from a slight notch to the complete formation of a pair of adjacent leaflets. This appears to me to be the best possible evidence that in this region. just above the base of the terminal leaflet, is the place of progressive differentiation and reintegration in pinnate leaves, and that it is here and not in the proximal leaflets that new characters are to be looked for. 
As further evidence that this is the correct interpretation of the pinnate leaf, the diagrams shown in figs. Io and II were constructed as follows: All the leaves of a single stem of Sium cicutaefolium (omitting several which had disappeared at the base) were arranged in their normal sequence, but side by side, with their rachises parallel and at equal intervals. These rachises are represented by the horizontal lines of the figures. The point of origin of each pair of leaflets was then marked, and the figures were completed by connecting with lines the points of origin of leaflets assumed to be homologous. In fig. Io the proximal leaflets, and in fig. I I the distal leaflets, are assumed to be homologous. The basis for the interpretation of these figures is to be found in the demonstration by Fräulein Tammes (I903) that the law of periodicity underlies all morphological phenomena in such a way that serially homologous characters increase regularly to a maximum and then decrease, decrease regularly to a minimum and then increase, or that they form a half period, $i$. e., they begin with the maximum and end with the minimum, or vice versa. Even a most superficial inspection of the two figures discloses the fact that in one there is a simple underlying law which would lend itself to ready formulation, while in the other all is confusion. The characters which are represented in these figures are the interfoliola or portions of the rachis between successive pairs of leaflets. Homologous interfoliola are represented by the portions of the horizontal lines included between any two consecutive curves. In fig. Io these interfoliola are seen to reach a definite maximum length in the second leaf from the base of the figure and to diminish continuously from that maximum upward until each in turn is reduced to zero, as required by the law of periodicity. The only irregularities appear in the two distal interfoliola of the third leaf from the base of the figure and in the distal interfoliolum of the first and of the fifth leaves from the base, these variations in the distal interfoliola being in full accord with my view that this is the region of active differentiation and reintegration in the leaf. In fig. II, on the other hand, there is not a single instance in which a serics of interfoliola assumed to be homologous shows an increase to a definite maximum followed by a continuous decrease. The law of periodicity is beautifully exemplified in fig. Io, which is based on the assumption that the proximal leaflets of one leaf are homologous with the proximal leaflets of every other leaf of the same stem, while there is no indication of that law in fig. II, in which the distal leaflets are assumed to be homologous. Certainly no more conclusive proof of the truth of my proposition could be asked.

As in the case of the juvenile and senescent leaves, the sole basis for the assumption that the base and apex of a leaf exhibit conditions which 
were characteristic of the whole adult leaf at some time in the past history of the species is the fact of their greater simplicity. The relation is purely a logical one, and the condition of these regions of the leaf are not unlikely to disagree with phylogenetic conditions in every detail except simplicity.

Although this study makes it evident that no satisfactory inferences can be drawn from the forms occurring at various ontogenetic stages regarding the ancestral adult conditions, these forms do have a bearing upon the relationship of allied species. The similarity of two species as to the characters possessed at any of these stages would lend evidence in favor of their close relationship in the same way that similarity in any other activity or character would, not because of resemblance to a common ancestral adult condition, but because of the presumptive evidence of similarity in present protoplasmic structure.

All the evidence now available indicates that when specific differentiation takes place the changed structure of the protoplasm which produces new adult characters also gives rise to new characters in the juvenile and senescent series. The assumption that these stages have a phylogenetic significance tends to obscure the fact that they are the results of present conditions instead of the past history of the protoplasm and that they are in need of physiological rather than phylogenetic investigation and interpretation. 


\section{SUMMARY.}

The various forms of leaf which occur at different parts of a specimen of Sium cicutaefolium are described and their bearing on the phylogenetic history of the species is considered. The principal conclusions are as follows:

There is great variability in the early nepionic leaves, the first leaf being the most variable and the variability being progressively lessened in subsequent growth.

The interpolation of an undivided leaf between the 3 -lobed and the pinnate leaf is illogical and might be interpreted as representing phylogenetic mutation.

To show how wholly gratuitous is the attempt to draw conclusions from juvenile stages regarding ancestral adult conditions, it is pointed out that in the species of Onagra, where the ancestry is definitely known, the juvenile leaves may resemble more closely the adult leaves of the same species than they do either the seedling or the adult leaves of the parent species.

The senescent stages are totally different from those of the seedling. The leaves show a regular reduction without sudden changes of type, and there is increasing constancy in form as higher stages are reached.

Although the several stages of Sium present the appearance of being closely correlated with the successive changes in its environment, the plant passes through the same stages whenever the conditions are favorable for growth, regardless of the characteristics in the environment which have been supposed to determine the several types of structure.

This cycle of development can be repeated only through rejuvenescence. This may result from fertilization and seed-production, but can be brought about in other ways. Rejuvenations of axillary buds and of flower-buds are figured and described. Rejuvenescence in these buds was caused by submergence in water of stems in the senescent state. The later the stage of senescence reached the earlier are the juvenile stages produced on rejuvenescence. Proliferations of flower-buds showed several leaf-forms which are simpler than any found in the seedlings.

Rejuvenescence may be due to increased available food-equivalent, or to increased lability or fluidity of the protoplasmic substances, or a combination of these two factors. The stage attained in any case of rejuvenescence may be due to the relative value of the resultant of these two complex factors, as compared with that necessary to the production of the climax type of leaf of the adult plant. 
It has been claimed that the apex of a leaf presents primitive conditions and that new leaf-characters appear at the base of the blade. It is shown here that the base is also "primitive" and that the new characters appear above the base.

The proximal leaflets of pinnate leaves on the same stem are homologous, as are all other pairs of leaflets having positions of like order, counting from the proximal pair.

The sole basis for the assumption that localized stages present atavistic characters is the fact of their greater simplicity. No satisfactory inferences can be drawn from ontogenetic leaf-characters regarding the phylogenetic history of the species. The various stages are the result of present protoplasmic structure instead of the past history of the protoplasm, and a change of structure which results in new adult characters may also produce changed juvenile and senescent characters. They are in need of physiological instead of phylogenetic interpretation.

Station for Experimental Evolution, Cold Spring Harbor, N. Y., December, 1904. 


\section{LITERATURE CITED.}

Agassiz, Louis.

I848-1849. Twelve lectures on comparative embryology. Boston: Lowell Institute.

Braun, Alexander.

I85I. Reflections on the phenomenon of rejuvenescence in nature, especially in the life and development of plants. Translation from the German, by A. Henfrey. London: Ray Society, I853.

Burns, GEORGE P.

1904. Heterophylly in Proserpinaca palustris L. Annals of Botany, 18: 579587.

Cushman, Joseph A.

1902. Studies of lacalized stages of growth in some common New England plants. Amer. Nat., 36: 865-885.

1903. Studies of localized stages in some plants of the botanic gardens of

Harvard University. Amer. Nat, 37: 2+3-259.

I904. Localized stages in common roadside plants. Amer. Nat., 38: 819-832.

Glaser, Otto C.

1902. The law of von Baer. Science, N. S., $15: 976-982$.

GoEBEL, KARL.

I898-I90I. Organographie der Pflanzen insbesondere der Archegoniaten und Samenpflanzen. pp. xviii, 838. Figs. 539. Jena: Gustav Fischer.

HAECKEL, ERNST.

I866. Generelle Morphologie der Organismen, 2 Bde. Berlin: G. Reimer.

Hyat', Alpheus.

I890. Genesis of the Arietidae. Smithsonian Contribution 673, and Mem. Mus. Comp. Zool., 16:

1897. Cycle in the life of the individual (ontogeny) and in the evolution of its own goup (phylogeny). Proc. Amer. Acad. Arts and Sciences, 32: 209-224.

JACKSON, R. T.

1899. Localized stages in development in plants and animals. Proc. Boston Soc. Nat. Hist., 5 : 89-153.

KLEBS, G.

1903. Willkürliche Entwicklungsänderungen bei Pflanzen. pp. iv, I66. Figs. 28. Jena: Gustav Fischer.

MCCalium, W. B.

1902. On the nature of the stimulus causing the change of form and structure in Proserpinaca palustris. Bot. Gaz., 34 : 93-108.

TAMMES, Fräulein Tine.

1903. Dic Periodicität morphologischer Erscheinungen bei den Pflanzen. Verhandelingen d. Koninklijke Akad. v. Wetenschappen te Amsterdam, 9 (No. 5) : I-I 48.

VON BAER, K. E.

1828. Ueber Entwicklungsgeschichte der Thiere. Beobachtungen und Reflexion. Königsberg: Gebr. Bornträger. 








\section{UNIVERSITY OF CALIFORNIA LIBRARY}

Los Angeles

This book is DUE on the last date stamped below. 
UC SOUTHERN REGIONAL LIBRARY FACILITY

AA 0008764219

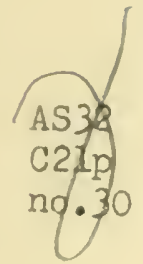


